\title{
Degradability, biocompatibility, and osteogenesis of biocomposite scaffolds containing nano magnesium phosphate and wheat protein both in vitro and in vivo for bone regeneration
}

\author{
This article was published in the following Dove Press journal: \\ International Journal of Nanomedicine \\ 26 July 2016 \\ Number of times this article has been viewed
}

Yan Xia'
Panyu Zhou',*
Fei Wang'
Chao Qiu'
Panfeng Wang'
Yuntong Zhang'
Liming Zhao
Shuogui Xu',2
'Department of Emergency,
'Department of Orthopedics,
Changhai Hospital, Second Military
Medical University, ${ }^{3}$ State Key
Laboratory of Bioreactor Engineering,
East China University of Science
and Technology, Shanghai, People's
Republic of China
*These authors contributed equally
to this work
to this work

\begin{abstract}
In this study, bioactive scaffold of nano magnesium phosphate (nMP)/wheat protein (WP) composite (MWC) was fabricated. The results revealed that the MWC scaffolds had interconnected not only macropores (sized 400-600 $\mu \mathrm{m}$ ) but also micropores (sized 10-20 $\mu \mathrm{m}$ ) on the walls of macropores. The MWC scaffolds containing $40 \mathrm{w} \% \mathrm{nMP}$ had an appropriate degradability in phosphate-buffered saline and produced a weak alkaline microenvironment. In cell culture experiments, the results revealed that the MWC scaffolds significantly promoted the MC3T3-E1 cell proliferation, differentiation, and growth into the scaffolds. The results of synchrotron radiation microcomputed tomography and analysis of the histological sections of the in vivo implantation revealed that the MWC scaffolds evidently improved the new bone formation and bone defects repair as compared with WP scaffolds. Moreover, it was found that newly formed bone tissue continued to increase with the gradual reduction of materials residual in the MWC scaffolds. Furthermore, the immunohistochemical analysis further offered the evidence of the stimulatory effects of MWC scaffolds on osteogenic-related cell differentiation and new bone regeneration. The results indicated that MWC scaffolds with good biocompability and degradability could promote osteogenesis in vivo, which would have potential for bone tissue repair.
\end{abstract}

Keywords: nano magnesium phosphate, wheat protein, composite scaffolds, degradation, bone regeneration

\section{Introduction}

Divalent cation of $\mathrm{Mg}$ plays critical roles in bone remodeling and skeletal tissue development of the human body, and in calcified tissues, $\mathrm{Mg}$ is involved in the calcification process. ${ }^{1,2} \mathrm{Mg}$ may improve bone mineral density and affect bone fragility, and lack of magnesium can affect all the stages of skeletal metabolism, leading to decreased bone growth and osteoporosis. ${ }^{3,4}$ Over the past few years, Mg-containing bioactive materials have received increased attention for bone tissue repair, and several magnesium-based biomaterials were reported, such as $\mathrm{Mg}$ and its alloys, magnesium-containing bioactive glasses and coatings, and Mg-substituted calcium phosphate bioceramics/biocements, and so on. ${ }^{5-8}$ These studies have shown that $\mathrm{Mg}$ as an important element in the bioactive materials can have some special effects on the material properties. ${ }^{9-11}$

Natural polymers (such as collagen, chitosan, plant protein, etc) are the most important raw materials for the development of biomedical materials. ${ }^{12}$ Wheat
Correspondence: Shuogui Xu Department of Emergency, Changhai Hospital, Second Military Medical University, No 168, Changhai Road, Yangpu District, Shanghai 200433,

People's Republic of China

Email xiayan20162@sina.com 
protein (WP) as an interesting natural polymer with excellent properties (good biocompatibility, degradability, etc) has been applied in many areas such as coating, encapsulation, and other medical applications. ${ }^{13,14}$ It was reported that the attachment and proliferation of osteoblasts on WP were better than poly(lactic acid) (PLA), and WP has been mixed with PLA and electrospun for biomedical applications. ${ }^{15,16}$ The potential of using WP-based composite with bioactive inorganic materials as scaffolds for bone tissue regeneration has not been studied. Calcium phosphate has been applied as biomedical material for bone regeneration for many years, whereas magnesium phosphate (MP) has not been applied so far. Therefore, in this study, nano magnesium phosphate (nMP) was fabricated and the bioactive scaffold of nMP/WP composite (MWC) was prepared. In addition, the in vitro degradability and cell growth on the MWC scaffolds were investigated. Furthermore, the in vivo osteogenesis and degradation properties of MWC scaffolds were also studied.

\section{Materials and methods}

\section{Fabrication and characterization of MWC scaffolds}

nMP was synthesized by a chemical precipitation method. Magnesium nitrate $\left(\mathrm{Mg}\left(\mathrm{NO}_{3}\right)_{2} \cdot 6 \mathrm{H}_{2} \mathrm{O}\right)$ and ammonium dihydrogen phosphate $\left(\mathrm{NH}_{4} \mathrm{H}_{2} \mathrm{PO}_{4}\right)$ were dissolved in deionized water. $\mathrm{Mg}\left(\mathrm{NO}_{3}\right)_{2} \cdot 6 \mathrm{H}_{2} \mathrm{O}$ solution was added dropwise to the $\mathrm{NH}_{4} \mathrm{H}_{2} \mathrm{PO}_{4}$ solution, while stirring, to produce a white precipitate; during the process, $\mathrm{pH}$ value was controlled around 9 with $\mathrm{NH}_{3} \cdot \mathrm{H}_{2} \mathrm{O}$ solution. After stirring for 12 hours, the precipitate was filtered and washed with distilled water for three times, and the precipitate was vacuum freeze dried at $-50^{\circ} \mathrm{C}$ for 16 hours. The resulting powder products were nMP. WP was purchased from Tokyo Chemical Industry Co., Ltd (Fujimi, Japan).

MWC scaffolds with nMP content of $40 \mathrm{w} \%$ were fabricated by solution casting-particle leaching method. Briefly, The WP powders were dissolved into absolute ethyl alcohol $\left(\mathrm{CH}_{3} \mathrm{CH}_{2} \mathrm{OH}\right)$ with the WP mass-to-solvent volume ratio of $20 \%(\mathrm{w} / \mathrm{v})$, and the mixture was stirred to obtain a homogeneous WP solution. The nMP powder was added into WP solution and sonicated for 1 hour to improve the dispersion of the nMP particles. After homogenization, the mixture was cast into the molds $(\Phi 12 \times 2$ and $\Phi 6 \times 6 \mathrm{~mm})$. The obtained samples were dried at $37^{\circ} \mathrm{C}$ for 48 hours to remove the solvent. After that, the samples were immersed into water for 48 hours at $37^{\circ} \mathrm{C}$ to leach out the $\mathrm{NaCl}$ particulates (water refreshed every 12 hours), and then the samples were dried at $37^{\circ} \mathrm{C}$ for 12 hours to obtain the MWC scaffolds. The WP scaffolds were prepared by the same method, which were used as controls. The phase compositions of the scaffolds were characterized by X-ray diffraction (Geigerflex; Rigaku Co. Ltd., Tokyo, Japan), and the surface morphology and microstructure of the scaffolds were observed by using scanning electron microscopy (S-4800N; Hitachi, Tokyo, Japan) and synchrotron radiation microcomputed tomography (SRmCT). The compressive strength of both the MWC and WP scaffolds was tested using a mechanical testing machine (HY-0230; Hanghai Heng Wing Precision Instrument Co., Ltd., Shanghai, People's Republic of China). Cylindrical scaffolds $(\Phi 6 \times 6 \mathrm{~mm})$ were loaded with a $1 \mathrm{kN}$ cell load at the speed of $1 \mathrm{~mm} / \mathrm{min}$ until crush, and the compressive strength was obtained from the peak of the stress-strain curve.

\section{In vitro degradability of the scaffolds}

The in vitro degradability of the MWC and WP scaffolds was determined by testing the weight loss ratio of the samples in phosphate-buffered saline (PBS). Briefly, the samples were weighed (Wi), immersed into PBS solution $(\mathrm{pH}=7.4)$ in sealed polyethylene bottles with a solid/liquid mass ratio of $0.1 \mathrm{~g} / 20 \mathrm{~mL}$, and incubated at $37^{\circ} \mathrm{C}$ with constant shaking at 100 rpm for 12 weeks. The PBS solution was refreshed every week. At preselected time point, the samples were removed from the solution and rinsed gently with deionized water. The samples were dried at $37^{\circ} \mathrm{C}$ until the water volatilized totally and were then weighed (Wf). The weight loss was calculated according to the following equation:

$$
\text { Weight loss }(\%)=\frac{\mathrm{Wi}-\mathrm{Wf}}{\mathrm{Wi}} \times 100
$$

The $\mathrm{pH}$ value of the PBS solution containing the scaffolds was measured using a pH meter (FE20K; Mettler Toledo, Küsnacht, Switzerland) at different time intervals.

\section{Cell proliferation, alkaline phosphatase activity, and morphology on the scaffolds}

The MC3T3-E1 cells were cultured in Dulbecco's Modified Eagle's Medium (HyClone; Thermo Fisher Scientific Inc., Waltham, MA, USA) supplemented with 10\% fetal bovine serum (GibcoBRL, Grand Island, NY, USA), 1\% penicillin $(100 \mathrm{U} / \mathrm{mL})$, and streptomycin sulfate $(100 \mathrm{mg} / \mathrm{mL})$ (GibcoBRL). The cells were cultured at $37^{\circ} \mathrm{C}$ in a humidified atmosphere of $5 \% \mathrm{CO}_{2}$ in air, and the culture medium was replaced every 2 days. 
The cell proliferation was determined using cell counting kit-8 (CCK-8) assay at 1, 3, and 7 days of culture using a standard procedure. Briefly, both MWC and WP scaffolds $(\Phi 12 \times 2 \mathrm{~mm})$ were sonicated in ethanol and sterilized using ultraviolet light. MC3T3-E1 cells with a density of $3 \times 10^{4}$ cells $/ \mathrm{mL}$ were seeded on the samples, which were placed into a 24-well plate. At each time point, the samples were gently rinsed with PBS $(\mathrm{pH}=7.4)$ three times and then transferred to a new 24-well plate. A total of $50 \mu \mathrm{L}$ of CCK-8 solution (Dojindo Molecular Technologies Inc., Kumamoto, Japan) was added to each well, and empty wells containing Dulbecco's Modified Eagle's Medium were set up as a blank control. After incubated for 3 hours, $10 \mu \mathrm{L}$ of the supernatant was transferred into a 96-well plate and read at $450 \mathrm{~nm}$ using a microplate reader (Synergy HT; Bio-tek, Winooski, VT, USA) with $620 \mathrm{~nm}$ as a reference wavelength. The mean absorbance values/optical density (OD) obtained from the blank control were subtracted from the ODs of the test groups.

Alkaline phosphatase activity of the MC3T3-E1 cells (density of $4 \times 10^{4}$ cells $/ \mathrm{mL}$ ) cultured on both the MWC and WP scaffolds $(\Phi 12 \times 2 \mathrm{~mm})$ was tested after 10 days. After incubation in a 24-well plate for 24 hours, the culture medium was refreshed to the osteogenic induction medium: the minimum essential medium alpha modified culture medium was supplemented with $10 \%$ fetal bovine serum, $0.1 \mu \mathrm{M}$ dexamethasone (Sigma-Aldrich Co., St Louis, MO, USA), $50 \mu \mathrm{M}$ ascorbate acid (Sigma-Aldrich Co.), and $10 \mu \mathrm{M} \beta$-glycerophosphate sodium (Sigma-Aldrich Co.). After cultured for 10 days, the scaffolds were washed three times with PBS, and lysed in a $0.2 \%$ TritonX-100 solution for four standard freeze-thaw cycles. The cell suspension was sonicated for 10 minutes and centrifuged at 2,000 rpm, and the p-nitrophenyl phosphate assay was carried out to obtain the OD value at $405 \mathrm{~nm}$ using microplate reader (SPECTR Amax 384; Molecular Devices LLC, Sunnyvale, CA, USA). Total protein content was determined using the bicinchoninic acid protein assay kits (Sigma-Aldrich Co.), and the ALP activity was expressed by OD value per total protein content.

The cell morphology was observed by detecting the filamentous actin of the cytoskeleton of MC3T3-E1 cells on scaffolds. After 24-hour incubation, the specimens were washed gently with PBS to remove the unattached cells. Then the cells on specimens were fixed with $4 \%$ paraformaldehyde for 15 minutes at room temperature and were permeabilized with $0.1 \%$ TritonX-100 in PBS for 10 minutes. After washed with PBS for three times, the cells were stained with 4,6-diamidino-2-phenylindole (DAPI;
Sigma-Aldrich Co.) and fluorescein isothiocyanate (FITC; Sigma-Aldrich Co.). The cell morphology was visualized using a confocal laser scanning microscopy (Nikon A1R; Nikon, Tokyo, Japan).

\section{Implantation of MWC scaffolds into femoral defects of rabbits}

\section{Animal experiments}

This study was approved by the Research Center for Laboratory Animal of Shanghai University of Traditional Chinese Medicine and followed the Chinese guidelines for animal care. Approximately 24 New Zealand white rabbits (male, $\sim 2.0 \mathrm{~kg}$ ) were chosen for surgery, in which 12 rabbits were used for MWC and WP scaffolds and four rabbits for each time point of 4, 8, and 12 weeks, respectively. Systemic anesthesia was achieved with $30 \mathrm{mg} / \mathrm{kg}$ pentobarbital sodium and local infiltration with articaine with 1:100,000 noradrenaline. A median incision was made on the left leg of the rabbit, and then a 6-mm radial defect was introduced in the thighbone of the rabbits. The bone defects were filled with the scaffold samples with the size of $\Phi 6 \times 6 \mathrm{~mm}$. Penicillin (4,000 units per body) and streptomycin ( $200 \mathrm{mg}$ per body) were administrated subcutaneously for the prevention of infection. After being implanted for 4, 8, and 12 weeks, rabbits were sacrificed with $3 \mathrm{~mL}$ intravenous pentobarbital solution, and bone samples were taken out and placed into $4 \%$ neutral buffered formalin.

\section{SRmCT analysis}

In order to evaluate the process of bone defect repair after the scaffold implantation, SRmCT measurements were performed at beam line BL13W of SSRF (Shanghai, People's Republic of China) using a monochromatic beam with an energy of $30 \mathrm{keV}$ and a sample-to-detector distance of $1.5 \mathrm{~m}$. In the current study, a $4,000 \times 2,500$ charge coupled device detector with the pixel size set to $6 \mu \mathrm{m}$ was used to record images. Approximately 1,500 projections within an angular range of $180^{\circ}$ were taken, and the exposure time amounted to 4 seconds per projection. Two-dimensional images were taken within a view of $6 \mathrm{~mm}$ in height, and the samples were scanned from top to bottom successively. Finally, the two-dimensional images of the whole samples were integrated by Adobe Photoshop CS5 Software (Adobe Systems Incorporated, San Jose, CA, USA). Three-dimensional (3D) images of the samples were reconstructed using a filtered back-projection algorithm. The images were converted into an eight-bit data format, proportional to the measured attenuation coefficients of the voxels. 


\section{Histological elevation}

After SRmCT scanning, the bone samples were decalcified in $10 \%$ ethylenediaminetetraaceticacid, $\mathrm{pH}=7.0$, for $\sim 30$ days at room temperature, and then washed with double-distilled water gently, dehydrated in ascending grades of alcohol, and embedded in paraffin. Serial section of all samples was made into a thickness of $20 \mu \mathrm{m}$ by a microtome and then frozen at $-20^{\circ} \mathrm{C}$. One section was selected for every ten sections, and hematoxylin and eosin (H\&E) staining was performed in $\sim 15$ sections of each sample. The new bone formation within scaffolds was observed under a light microscope (TE2000U; Nikon). In addition, the decalcified sections were also stained with Masson trichrome and then observed with a light microscope.

Statistical analysis of the histological sections was performed to quantitatively determine the amount of newly formed bone at 4, 8, and 12 weeks. Three pieces of histological sections were randomly selected from both the MWC and WP scaffolds. After H\&E staining or Masson trichrome staining, each section was observed under light microscope at $10 \times$ and $20 \times$ magnifications, and at least six images were randomly obtained in the same section. Using image analytical software Image-ProPlus (Media Cybernetics, Rockville, MD, USA), new bone area was expressed as percentage of newly formed bone area within the original bone defect area. Furthermore, by Masson trichrome staining, quantitative analysis was performed by using the same image analytical software Image-ProPlus to determine the mature bone ratio and material residual ratio after the scaffold implantation for 4,8 , and 12 weeks (at least six images were randomly obtained in the same histological section).

\section{Immunohistochemical analysis}

Decalcified histological sections were mounted on aminopropyl-triethoxy-silane-coated slides. These sections were then dewaxed in descending concentrations of alcohol and rehydrated. The slides were immersed in 3\% hydrogen peroxide to block endogenous peroxidases and rinsed in PBS. Then they were immersed in $0.1 \%$ TritonX-100 in PBS for 20 minutes in order to allow the membrane to penetrate. Antigen retrieval was carried out in a $10 \mathrm{mM}$ at $60^{\circ} \mathrm{C}$ warm citrate buffer for 15 minutes at $\mathrm{pH}$ 6.0. Afterward, the slides were rinsed gently with PBS. Specific sites were saturated with normal goat serum for 40 minutes at $37^{\circ} \mathrm{C}$. The sections were incubated with the specific antisera (all diluted 1:100) overnight at $4^{\circ} \mathrm{C}$.

The histological sections were deparaffinized and incubated with primary antibodies against bone morphogenetic protein-2 (BMP-2, 1:25 dilution; Abcam, Inc., Cambridge, UK) to identify osteogenesis before applying fluorescent donkey polyclonal second antibody IgG (diluted 1:200; Thermo Fisher Scientific) for 30 minutes at room temperature. Thereafter, the sections were incubated for 30 minutes with DAPI for counterstaining. The slides were then examined microscopically (TE2000U; Nikon).

\section{Statistical analysis}

All quantitative data expressed as the mean \pm standard deviation $(\mathrm{M} \pm \mathrm{SD}$ ) were analyzed with Origin 8.0 (Origin Lab Corporation, Northampton, MA, USA). Statistical comparisons were carried out using analyses of variance. A minimum of three samples per group was tested for degradability in vitro, and five parallel samples per group were tested for the cell experiments. Statistical significance was attained with $>95 \%$ confidence level $(P<0.05)$.

\section{Results \\ Characterization of MWC scaffolds}

Figure 1A illustrates the transmission electron microscope of nMP, showing that the nMPs were spherical-like particles with the size of $\sim 100 \mathrm{~nm}$. Figure 1B shows the photos of MWC scaffolds. Figure 1C shows the 3D reconstructed image of SRmCT for MWC scaffold, and it can be seen that the MWC scaffold exhibited a well-interconnected porous structure. Figure 1D shows the X-ray diffraction of MWC scaffold. The X-ray diffraction of WP, was used as a control). It can be seen that the peaks at $2 \theta=12.2^{\circ}, 13.5^{\circ}, 21.1^{\circ}, 23.2^{\circ}$, $29.6^{\circ}, 31.4^{\circ}, 34.7^{\circ}, 36.4^{\circ}$, and $40.8^{\circ}$ are attributed to $\mathrm{nMP}$, and a wide peak at around $2 \theta=20^{\circ}$ belongs to WP. The results indicated that the nMP was weak crystalline while WP was an amorphous material (no sharp peak).

Figure 2 shows the scanning electron microscopy images of surface morphology of the MWC and WP scaffolds. It can be seen that both the MWC and WP scaffolds showed well-interconnected macroporous structures with the macropores of size ranging from 400 to $600 \mu \mathrm{m}$, and micropores of size ranging from 10 to $20 \mu \mathrm{m}$ on the walls of the macropores. The surface morphology of MWC scaffolds showed slightly coarse because of the introduction of nMP particles, while the WP scaffolds exhibited a smooth surface. Moreover, the compressive strength of the MWC and WP scaffolds were 1.8 and $1.1 \mathrm{MPa}$, respectively. The results indicated that the addition of nMP into WP improved the compressive strength of the MWC scaffolds. 

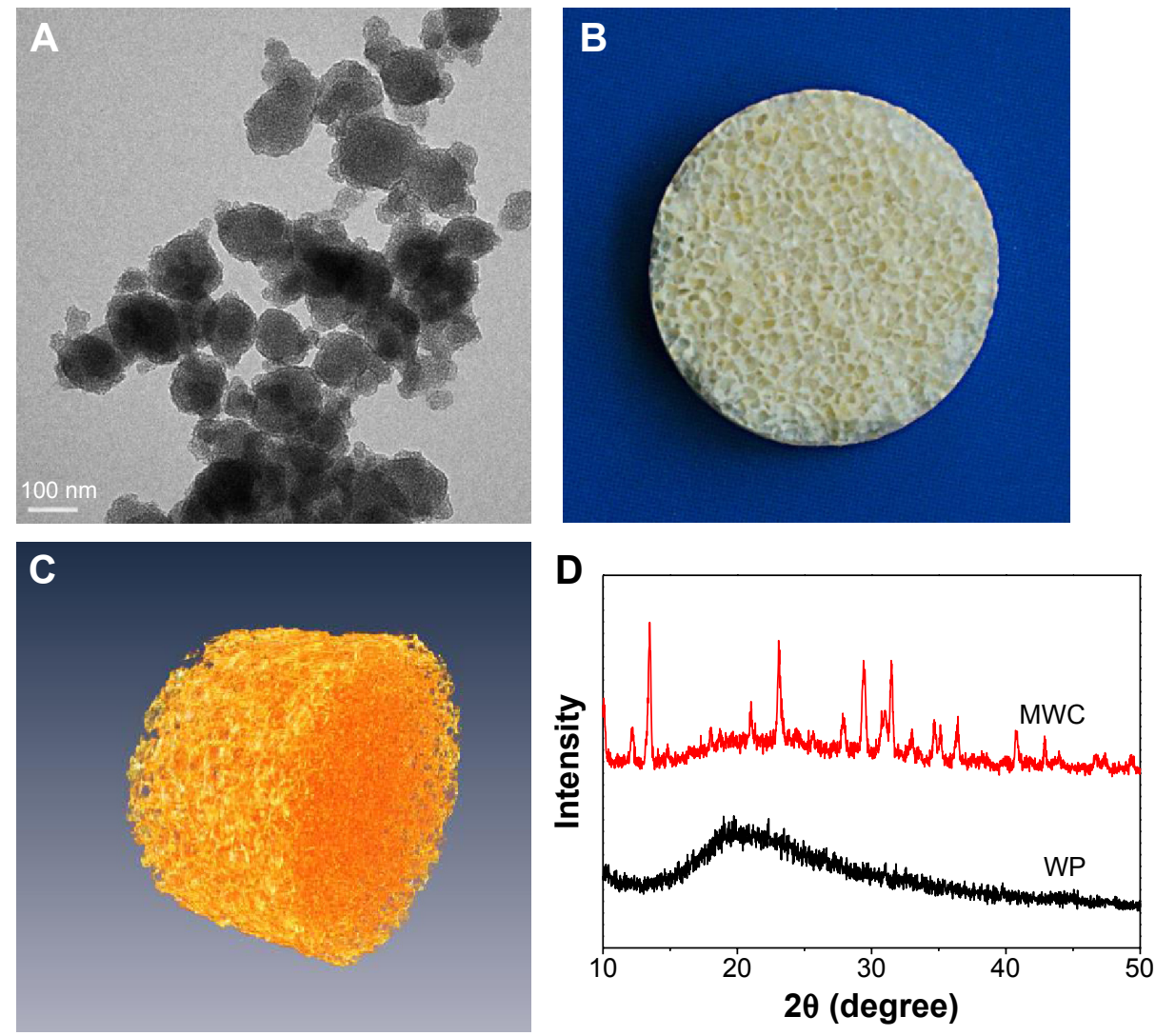

Figure I Nano magnesium phosphate (magnification 200,000) (A), photographs of MWC scaffold (B) and SRmCT 3D reconstruction image of MWC scaffold (C), and XRD of MWC scaffolds (D) (WP as a control).

Abbreviations: MWC, nano magnesium phosphate/wheat protein composite; SRmCT, synchrotron radiation microcomputed tomography; WP, wheat protein; XRD, X-ray diffraction; 3D, three dimensional.
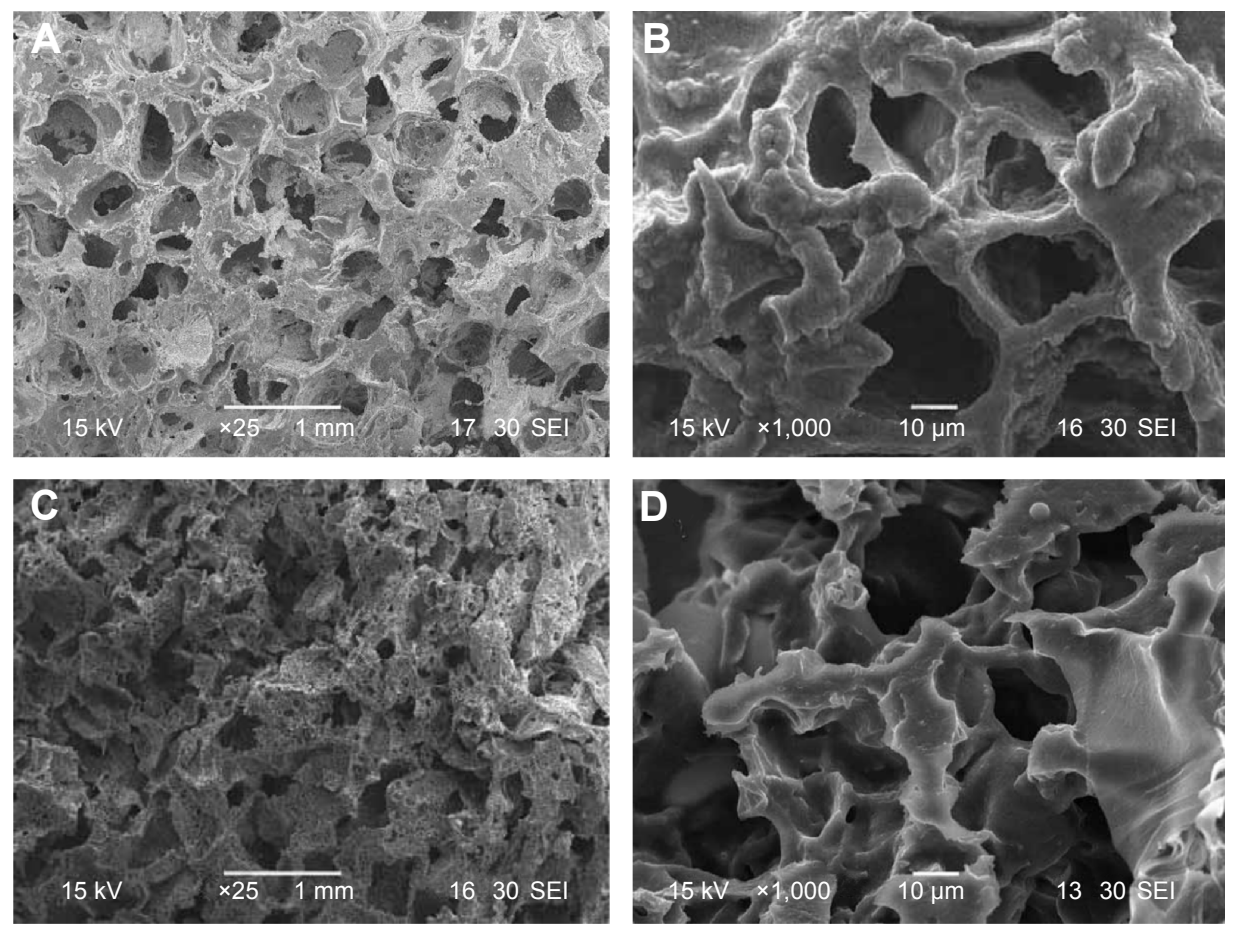

Figure 2 SEM images of MWC scaffolds ( $\mathbf{A}$ and $\mathbf{B}$ ) and WP scaffolds ( $\mathbf{C}$ and $\mathbf{D}$ ) with different magnifications.

Abbreviations: MWC, nano magnesium phosphate/wheat protein composite; SEM, scanning electron microscopy; WP, wheat protein. 

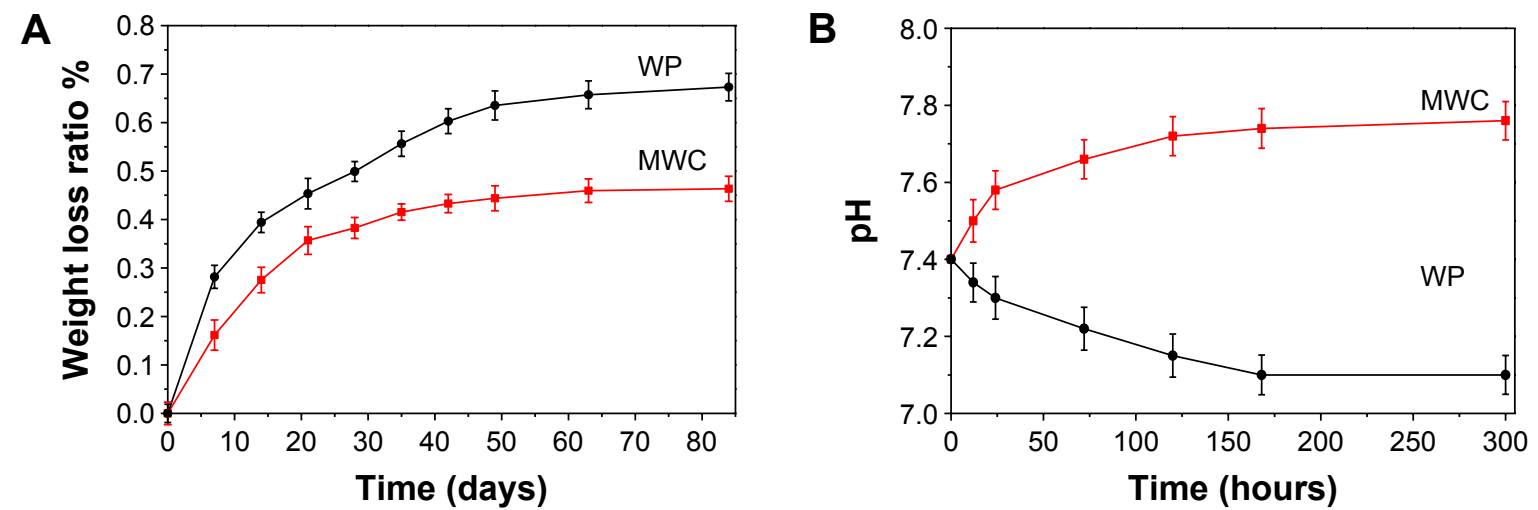

Figure 3 Weight loss (A) of the MWC and WP scaffolds immersed in PBS solution, and pH change (B) of the solution after MWC and WP scaffolds immersed in PBS solution with time.

Abbreviations: MWC, nano magnesium phosphate/wheat protein composite; PBS, phosphate-buffered saline; WP, wheat protein.

\section{In vitro degradability and $\mathrm{pH}$ change of MWC scaffolds}

Figure 3A shows the weight loss ratio of the MWC scaffolds after immersion into PBS solution for different time intervals. It is found that the weight loss ratio of MWC scaffolds increased with the time. In addition, the weight loss ratio of MWC scaffolds reached $46.34 \mathrm{w} \%$, while WP scaffolds was $67.32 \mathrm{w} \%$ after soaking for 12 weeks. The results indicated that the MWC scaffolds containing nMP had a slower degradation rate than WP scaffolds.

Figure $3 \mathrm{~B}$ shows the $\mathrm{pH}$ change of the solution after MWC scaffolds immersed into PBS for different time intervals. It is found that the $\mathrm{pH}$ of the solution for $\mathrm{MWC}$ scaffolds increased from 7.40 (initial) to 7.76 (at 300 hours) while the $\mathrm{pH}$ for WP scaffolds reduced from 7.40 (initial) to 7.10 (at 300 hours). The results indicated that MWC scaffolds contained MP increased the $\mathrm{pH}$ of the solution while WP scaffolds slightly decreased the $\mathrm{pH}$ after being immersed into PBS for 300 hours as compared with the initial pH of PBS.

\section{Cell proliferation, alkaline phosphatase activity, and morphology on MWC scaffolds}

Figure 4 shows the cell proliferation of MC3T3-E1 cells on both the MWC and WP scaffolds elevated by CCK-8 assay. The relative proliferation rate of cells on the two scaffolds increased with time. There was no obvious difference in cell proliferation between MWC and WP scaffolds after 1 and 3 days. However, the relative proliferation rate of cells on MWC scaffolds was obviously higher than WP scaffolds after 7 days $(P<0.05)$. The result indicated that the MWC scaffolds promoted cell proliferation.
The ALP activities of the cells on scaffolds after 10 days are shown in Figure 5. It could be observed that the ALP activity of cells on the MWC showed significantly higher than that on WP scaffolds at 10 days. The results revealed that the MWC scaffolds promoted cell differentiation.

Figure 6 illustrates the confocal laser scanning microscopy images of the MC3T3-E1 cell growth into the scaffolds stained by fluorescein isothiocyanate and DAPI, which displayed limpid F-actin including microfilaments after incubation for 24 hours. The results revealed that the cells exhibited a typical fibroblastic morphology with more and apparent cytoplasmic extensions and filopodial attachments in the scaffolds, and the cell numbers in the MWC scaffolds were more than those in WP scaffolds. However, the actin cytoskeleton formation in the WP scaffolds distributed irregularly and in short fiber concentration.

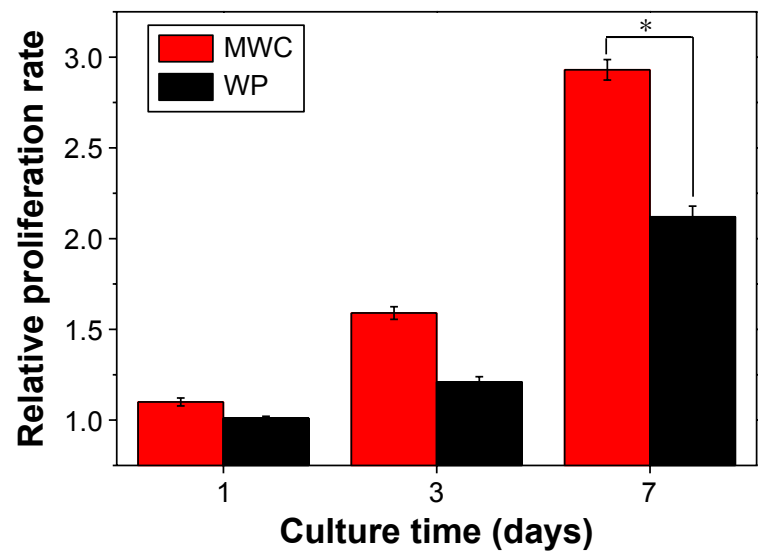

Figure 4 Proliferation of MC3T3-EI cells cultured on MWC and WP scaffolds at different time intervals.

Note: $* P<0.05$

Abbreviations: MWC, nano magnesium phosphate/wheat protein composite; WP, wheat protein. 


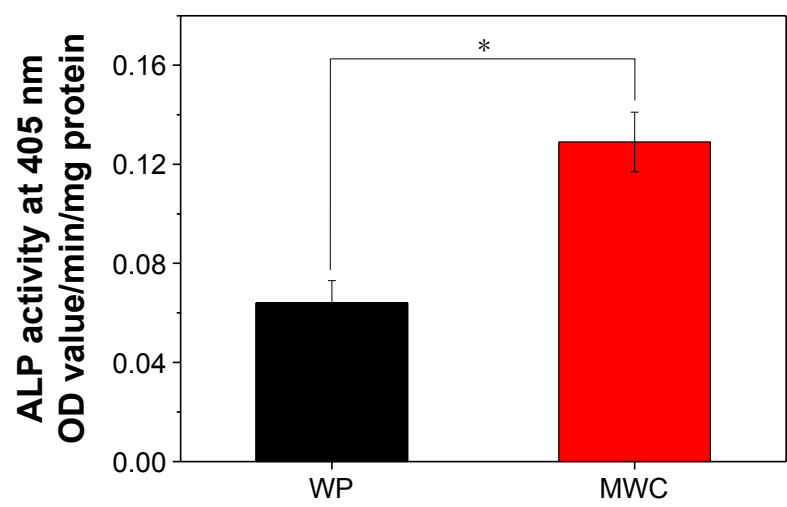

Figure 5 Alkaline phosphatase (ALP) activity of MC3T3-El cells cultured on MWC and WP scaffolds at 10 days.

Note: $* P<0.05$.

Abbreviations: MWC, nano magnesium phosphate/wheat protein composite; WP, wheat protein; OD, optical density.

\section{Implantation of MWC scaffolds into femoral defects of rabbits \\ Macro observation and SRmCT analysis}

No postoperative inflammation or complications were observed after the MWC scaffolds implanted into the femoral defects of rabbits. Figure 7 shows the photographs of the appearance of the bone defects implanted with MWC scaffolds at 4,8 , and 12 weeks. It can be seen that the bone defects were gradually restored with time. After 12 weeks, the bone defects were renovated by MWC scaffolds while the bone defects were not completely renovated by WP scaffolds. Figure 8 shows the SRmCT slice images of the MWC scaffolds implanted into the bone defects for 4, 8, and 12 weeks and WP scaffolds implanted for 12 weeks. It can be seen that the bone defect area gradually diminished after the MWC scaffolds implanted for 4 and 8 weeks. After implanted for 12 weeks, the bone defects were completely disappeared. However, the bone defects were not completely repaired after implantation of WP scaffolds. Figure $8 \mathrm{E}$ and $\mathrm{F}$ shows the SRmCT 3D reconstructed images of MWC scaffolds implanted into bone defects for 12 weeks. It can be seen that the effectiveness of bone defects repair by MWC scaffolds was better than WP scaffolds, indicating that the MWC scaffolds exhibited favorable bone regeneration ability as compared with WP scaffolds.

\section{Histological elevation}

Figure 9A shows the images of histological sections (H\&E staining) of MWC scaffolds implanted into the femoral defects of rabbits for 4,8 , and 12 weeks and WP scaffolds implanted for 12 weeks. After 4-week postimplantation, a few newly formed bone tissues were found in the MWC scaffolds. After implantation for 8 weeks, the newly formed bone tissue gradually increased. After implantation for 12 weeks, a large amount of newly formed bone tissues were observed in the MWC scaffolds, and bone marrow was also observed. Meanwhile, after 12-week postimplantation, some newly formed bone tissues were also found in the WP scaffolds.

Figure 9B shows the change of ratio of new bone area in both the MWC and WP scaffolds at different time intervals. It is found that the new bone area increased with the implantation time for the two scaffolds. At 4 weeks, there was no obvious difference in the new bone area between the MWC and WP scaffolds. However, at 8 and 12 weeks, the new bone area for MWC scaffolds (58.5\% and $92.8 \%$, respectively) were obviously higher than that for WP scaffolds $(32.3 \%$ and 55.6\%, respectively) $(P<0.05)$.

Figure 10A shows the images of histological sections (Masson trichrome staining) of MWC scaffolds implanted in vivo for 4, 8, and 12 weeks and WP scaffolds implanted
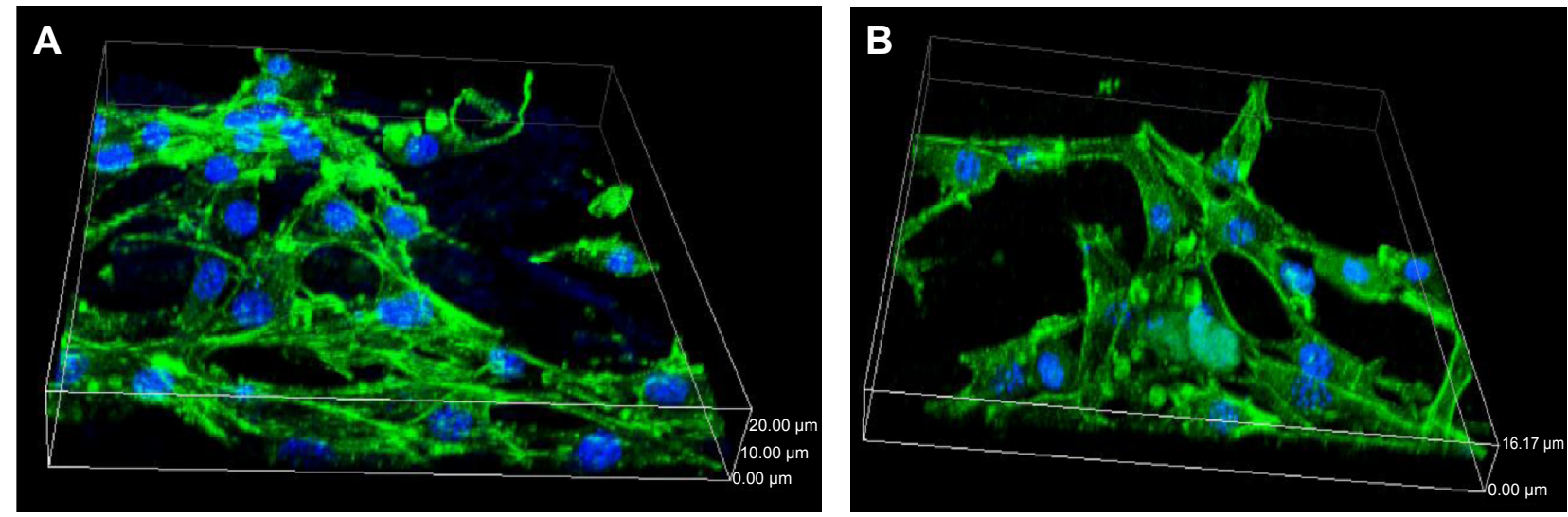

Figure 6 CLSM of cytoskeleton stained by FITC and DAPI after MC3T3-EI cells were cultured on MWC (A) and WP (B) scaffolds at 24 hours.

Abbreviations: CLSM, confocal laser scanning microscopy; DAPI, 4,6-diamidino-2-phenylindole; FITC, fluorescein isothiocyanate; MWC, nano magnesium phosphate/wheat protein composite; WP, wheat protein. 

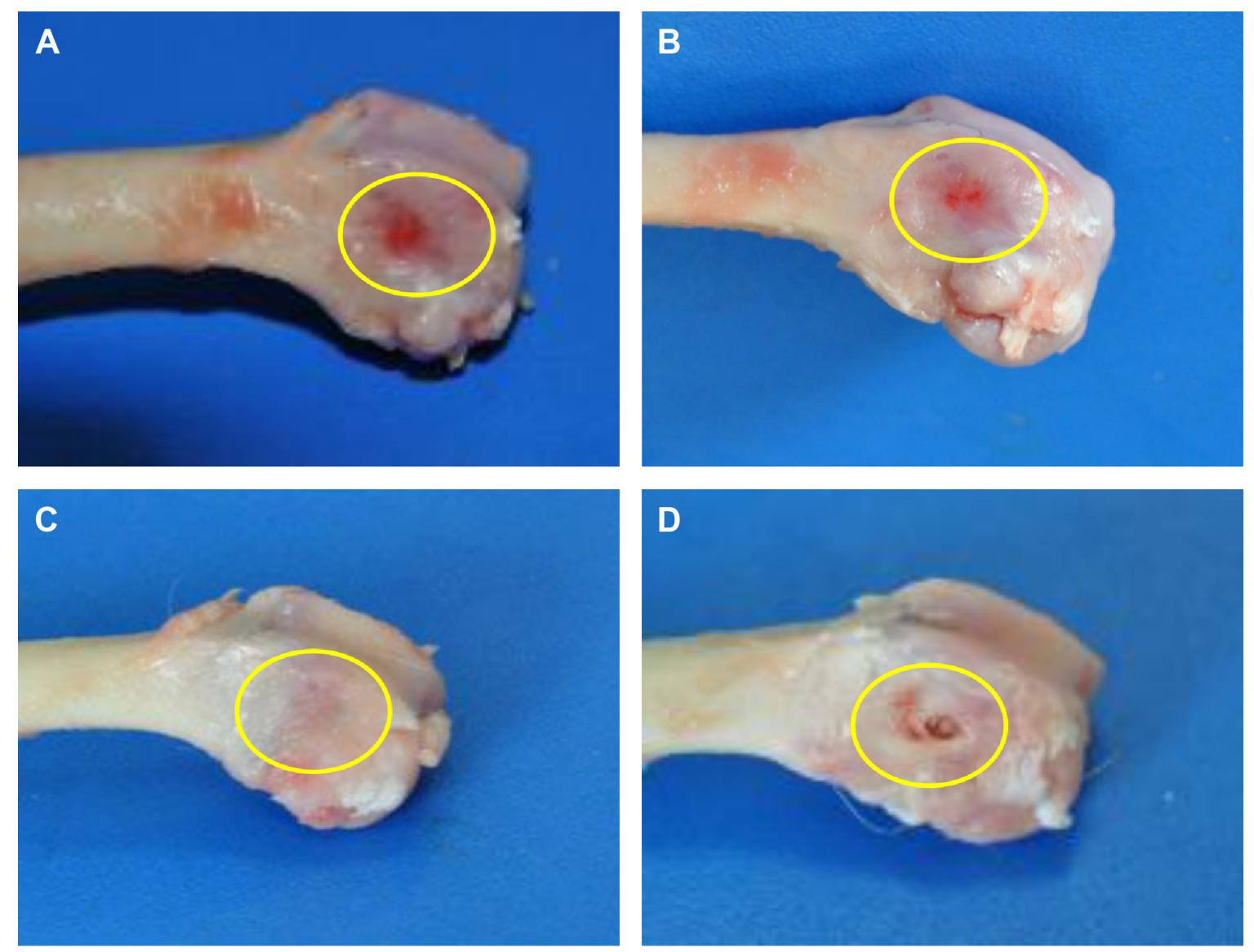

Figure 7 Photos of MWC scaffolds implanted into the femoral defects (yellow circle) of rabbits for 4 (A), 8 (B), and I2 (C) weeks and WP scaffolds implantation for 12 (D) weeks.

Abbreviations: MWC, nano magnesium phosphate/wheat protein composite; WP, wheat protein.

in vivo for 12 weeks, which provided the supplementary information for H\&E staining. At 4 weeks, only a few new bone tissues were found, and a large amount of materials were observed for the MWC scaffolds. At 8 weeks, new bone tissue gradually increased and the materials obviously decreased as compared with 4-week postimplantation. At 12 weeks, a large amount of new bone tissue and mature bone were found and the materials almost disappeared for the MWP scaffolds. Meanwhile, some new bone tissues were also found for the WP scaffolds, but there was no mature bone, and the materials nearly disappeared.

Figure10B shows the change of ratio of new bone, mature bone, and material residual (based on Masson trichrome staining) with time after the MWC and WP scaffolds implanted in vivo. It is found that the new bone ratio and mature bone ratio increased with time while the material residual ratio decreased with time. After implanted for 12 weeks, the osteogenesis ratio, mature bone ratio, and residual ratio for the MWC scaffolds were $86 \%, 8 \%$, and $0 \%$ while for the WP scaffolds were $61 \%, 2 \%$, and $0 \%$, respectively. The results indicated that the new bone ratio and mature bone ratio for the MWC scaffolds were significantly higher than WP scaffolds, and both the MWC and WP scaffolds degraded completely in vivo at 12 weeks.

\section{Immunohistochemical analysis}

Figure 11A shows the histological section of immunohistochemical staining of BMP-2 after the MWC scaffolds implanted in vivo for 4,8 , and 12 weeks. It is found that the BMP-2 staining intensity (brown) increased with time, indicating that the positive expression of BMP-2 gradually increased with the time. At 12 weeks, the positive expression of BMP-2 for MWC scaffolds was obviously higher than WP scaffolds, indicating that the osteogenesis properties for the MWC scaffolds was significantly better than those for the WP scaffolds.

Figure 11B shows the change of positive expression ratio of BMP-2 for both the MWC and WP scaffolds with time. The positive expression ratios for the MWC scaffolds were 7.9\%, $36.3 \%$, and $62.7 \%$ while for the WP scaffolds were $7.1 \%$, $22.5 \%$, and $36.1 \%$ at 4,8 , and 12 weeks, respectively. The results indicated that the positive expression ratio of BMP-2 

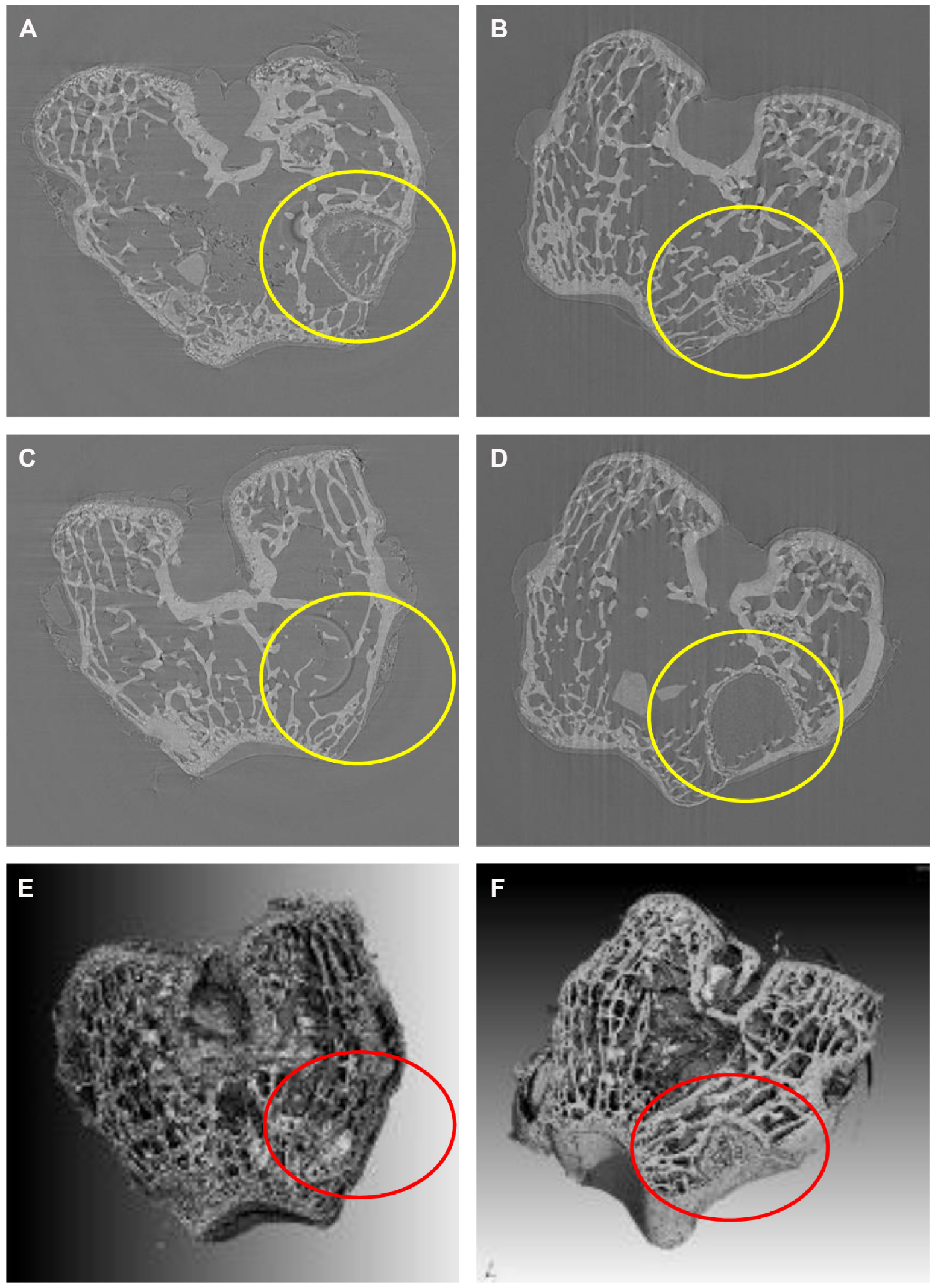

Figure $8 \mathrm{SRmCT}$ images of central virtual slice of MWC and WP scaffolds and cross-section of 3D reconstruction SRmCT images of MWC and WP scaffolds. Notes: SRmCT images of central virtual slice of MWC scaffolds implanted into the femoral defects (yellow circle) of rabbits for 4 (A), 8 (B), and 12 (C) weeks and WP scaffolds implantation for I2 (D) weeks. Cross-section of 3D reconstruction SRmCT images of MWC scaffolds (E) and WP (F) scaffolds implanted into the femoral defects of rabbits for 12 weeks, and the red circles describe the defects.

Abbreviations: 3D, three dimensional; MWC, nano magnesium phosphate/wheat protein composite; SRmCT, synchrotron radiation microcomputed tomography; WP, wheat protein. 
A

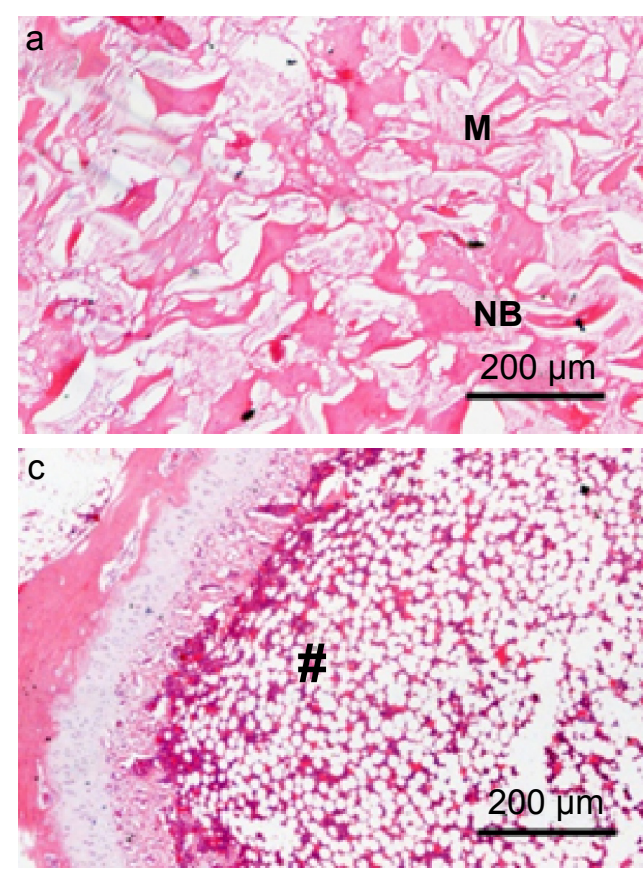

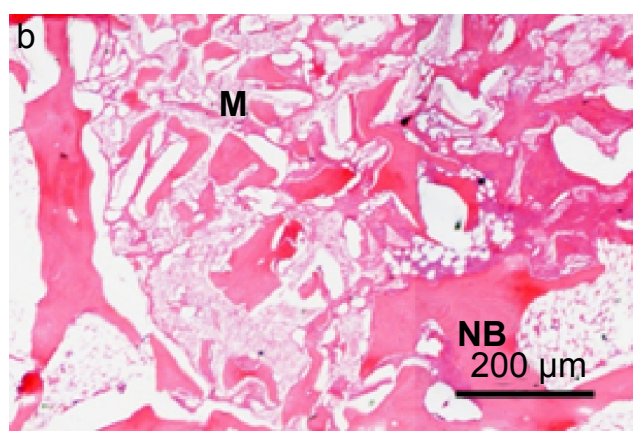

d

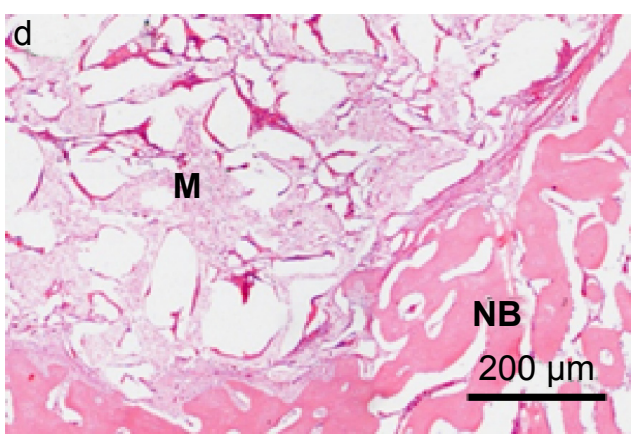

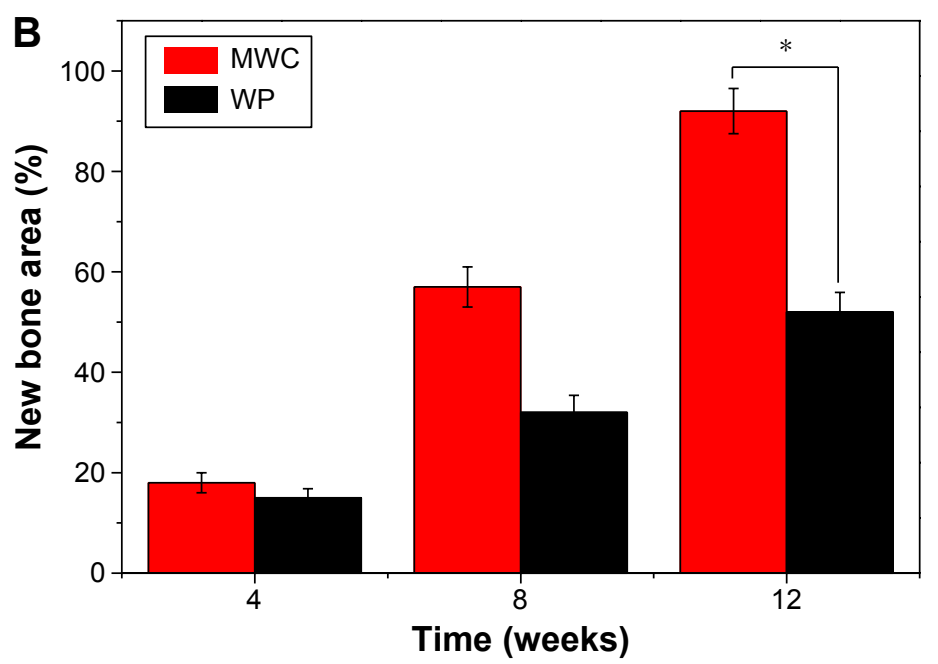

Figure 9 Histological section of bone regeneration area.

Notes: (A) Histological section (H\&E staining) of new bone formation and material degradation after MWC scaffolds implanted into the femoral defects of rabbits for 4 (a), 8 (b), and 12 (c) weeks and WP scaffolds implantation for 12 (d) weeks. NB represents new bone, M represents materials, and \# represents bone marrow (magnification I00X). (B) Quantitative comparison of the percentage of new bone formation after MWC scaffolds and WP scaffolds implanted in vivo for 4, 8 , and I2 weeks. *P $<0.05$. Abbreviations: H\&E, hematoxylin and eosin; MWC, nano magnesium phosphate/wheat protein composite; WP, wheat protein.

for both the MWC and WP scaffolds increased with time, and no obvious difference was found for two scaffolds at 4 weeks. However, the positive expression ratio of BMP-2 for the MWC scaffolds was obviously higher than that for the WP scaffolds at 8 and 12 weeks.

\section{Discussion}

In the past few years, Mg-containing bioactive materials have attracted significant attention for bone repair and bone tissue engineering applications due to their excellent bioactivity and osteostimulation. ${ }^{17}$ It is known that scaffolds for bone tissue regenerations play an important role in influencing the biological responses of cells (including attachment, proliferation, differentiation, etc) and the following new bone tissue formation (scaffolds entirely degraded) in vivo. ${ }^{18,19}$ In this study, MWC scaffolds were fabricated using solution casting-particle leaching method. The results revealed that the MWC scaffolds exhibited a well-interconnected macroporous structure, and some micropores were found on the wall of the macropores. The micropore/macropore structures might improve the surface area of the scaffolds, which would be suitable for bone tissue ingrowth. ${ }^{18}$ 

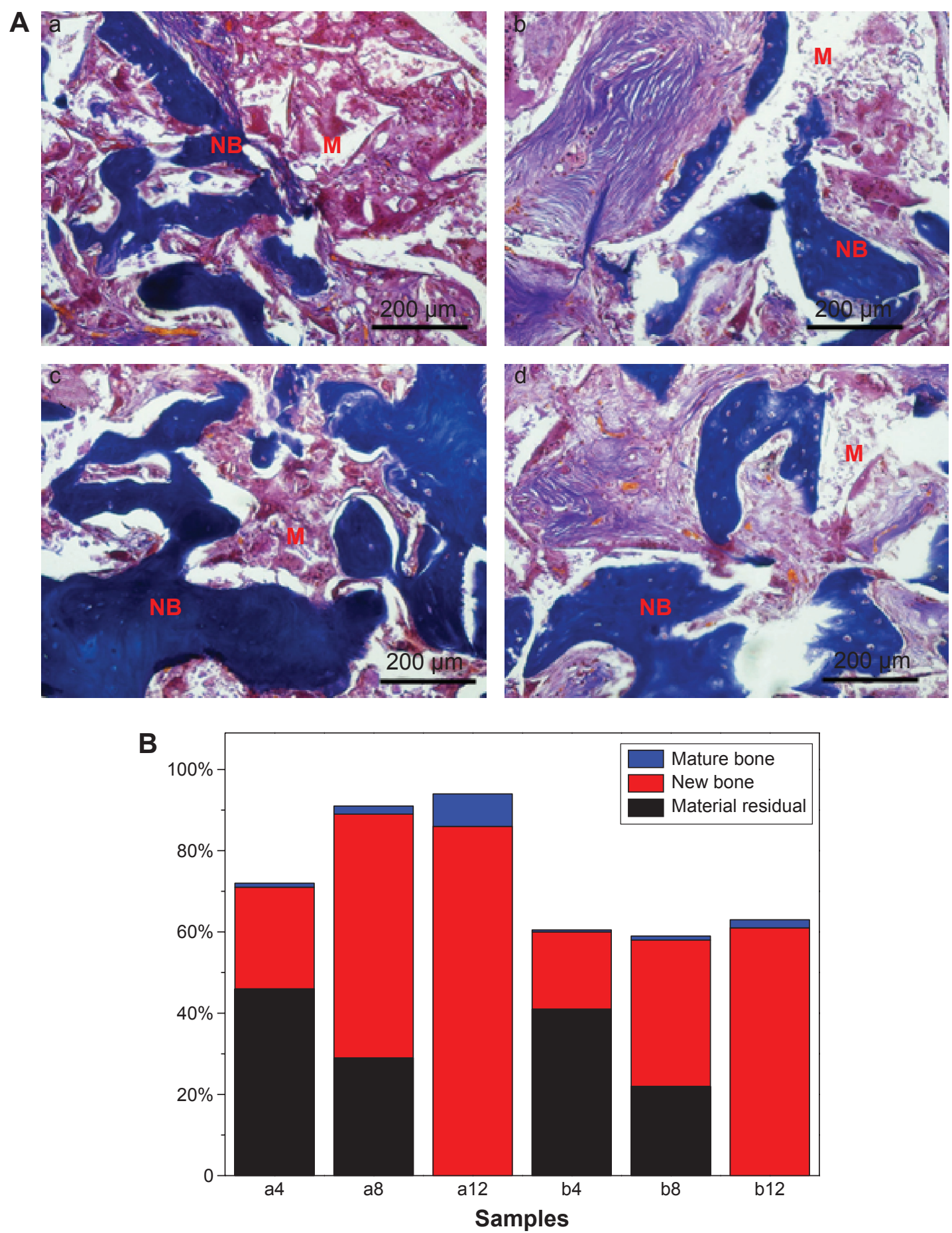

Figure 10 Masson trichrome staining of new bone area.

Notes: (A) Histological section (Masson trichrome staining) of new bone formation and materials degradation after MWC scaffolds implanted in the femoral defects of rabbits for 4 (a), 8 (b), and I2 (c) weeks and WP scaffolds implantation for I2 (d) weeks. NB represents new bone, M represents materials (magnification I00X). (B) Change of ratio of mature bone, new bone, and material residual with time after MWC scaffolds and WP scaffolds implanted in vivo for 4, 8, and I2 weeks.

Abbreviations: MWC, nano magnesium phosphate/wheat protein composite; WP, wheat protein.

In designing a scaffold for bone tissue regeneration applications, appropriate degradation is a significant factor that must be taken into consideration. ${ }^{20}$ Ideally, the scaffolds should have the degradation rate matching the new bone tissue growth and gradually replaced by new bone tissue around 3 months. ${ }^{21}$ In this study, it was found that the weight loss of MWC scaffolds was $46.34 \mathrm{w} \%$ after immersion into PBS for 12 weeks, indicating that the degradability of the MWC scaffolds might be suitable for new bone tissue formation. However, the weight loss of WP scaffolds was $67.32 \mathrm{w} \%$, indicating that the degradation rate of the WP scaffolds might be too fast to match the new bone tissue formation and repair 

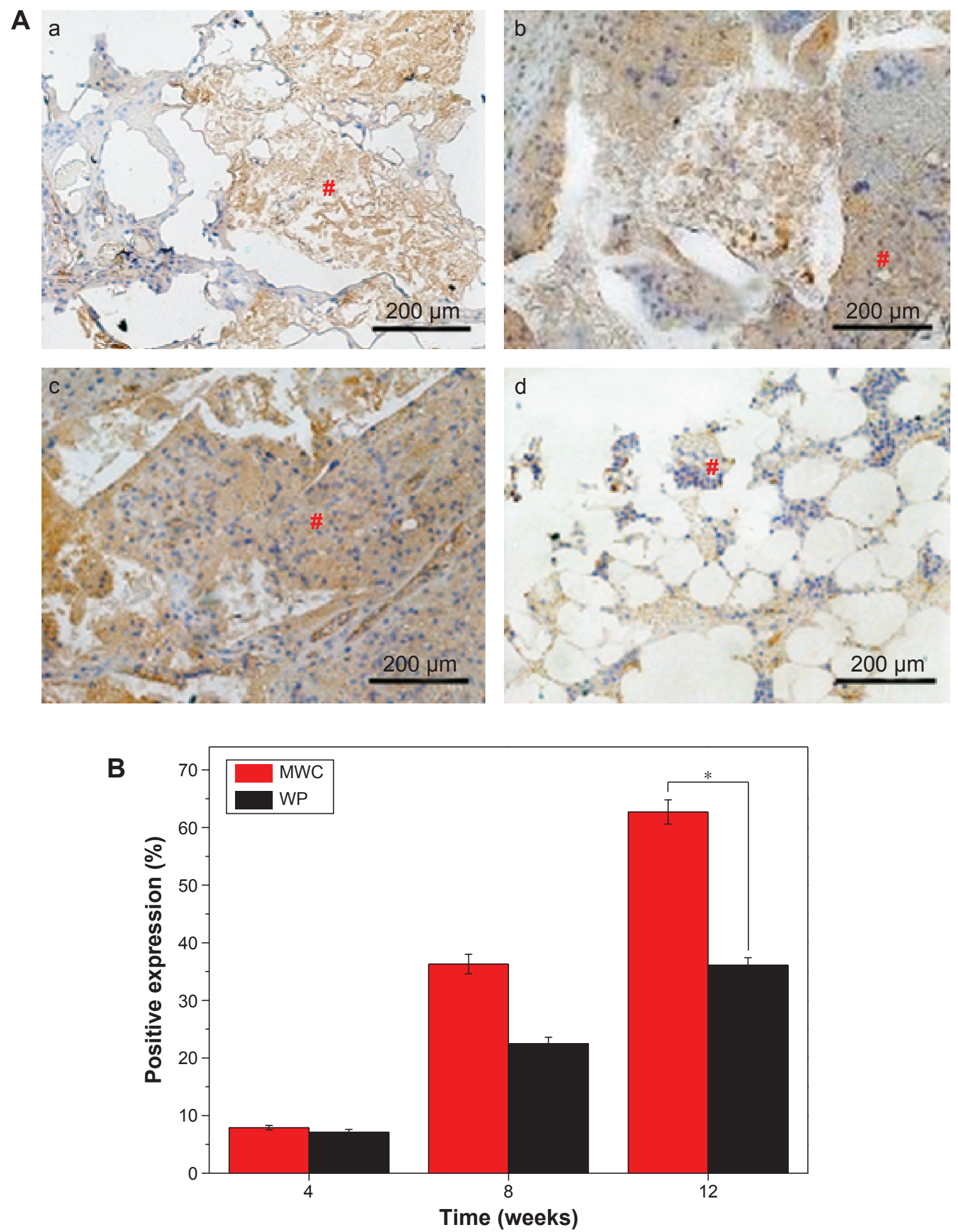

Figure II Immunohistochemical analysis of new bone tissue.

Notes: (A) Histological sections of immunohistochemical staining of positive expression of BMP-2 after MWC scaffolds implanted in vivo for 4 (a), 8 (b), and I2 (c) weeks and WP scaffolds implanted in vivo for 12 (d) weeks, \# brown areas represent positive expression of BMP-2 (magnification I00X). (B) Change of positive expression ratio with time after MWC scaffolds and WP scaffolds implanted in vivo for 4,8 , and 12 weeks. $* P<0.05$.

Abbreviations: BMP-2, bone morphogenetic protein-2; MWC, nano magnesium phosphate/wheat protein composite; WP, wheat protein.

bone defects. The results also suggested that altering the nMP content in the MWC scaffolds could adjust the degradability rate of the scaffolds, which was highly significant for bone tissue ingrowth and new bone formation. ${ }^{22}$
It is known that the release of acidic degradation by-products from some degradable polymers could lead to inflammatory responses in vivo, and many methods have been tried to control the $\mathrm{pH}$ decrease during the degradation of these 
polymers. ${ }^{23,24}$ In this study, it was found that there was gradually a decrease of $\mathrm{pH}$ in the solution containing WP (from 7.40 to 7.10), indicating that some acidic products (amino acids) might be produced from WP degradation during the soaking process. However, the $\mathrm{pH}$ for MWC scaffolds showed a slight increase from the initial value of 7.40 to 7.76 during the soaking process. The results indicated that MWC scaffolds containing nMP could neutralize the acidic degradation products from WP and thus compensated for the decrease of $\mathrm{pH}$ value. The increasing $\mathrm{pH}$ of the solution containing MWC scaffolds might be correlated to the dissolution of alkaline ions $\left(\mathrm{Mg}^{2+}\right)$ from the nMP that locally compensated for the acidification of the solution due to the acidic products from WP degradation. ${ }^{25}$ Moreover, a study has shown that weak alkaline condition provided a better microenvironment for cell proliferation and subsequently differentiation. ${ }^{26}$ Therefore, the MWC scaffolds may supply a good microenvironment for cell ingrowth both in vitro and in vivo.

The cellular responses to the biomaterials, such as attachment and proliferation, depend not only on surface morphology but also on surface chemistry. ${ }^{27}$ In this study, the proliferation of MC3T3-E1 cells on the MWC scaffolds increased with time, and the proliferation of the cells on the MWC scaffolds was significantly higher than that on the WP scaffolds. In addition, the ALP activity of cells on the MWC scaffolds showed significantly higher than that on the WP scaffolds, revealing that the addition of nMP into WP promoted cell differentiation. Furthermore, the confocal laser scanning microscopy images showed that the cells grew into the scaffolds, and the cell numbers in the MWC scaffolds were more than those in the WP scaffolds. The results suggested that the MWC scaffolds showed better cytocompatibility for cell adhesion, proliferation, differentiation, and ingrowth as compared with the WP scaffolds. Previous studies have shown that the $\mathrm{Mg}$ ion dissolution products from bioactive glasses and bioceramics could stimulate osteoblasts proliferation and differentiation. ${ }^{28}$ In this study, the continuous degradation of the MWC scaffolds might produce a $\mathrm{Mg}$ ion-rich microenvironment that might be responsible for stimulating cell proliferation and differentiation.

Since MWC scaffolds showed excellent in vitro degradability and cytocompatibility, we further investigated in vivo osteogenesis and biocompatibility of MWC scaffolds implanted into femur defects of rabbits for different time intervals. The SRmCT results demonstrated that the bone defects were gradually repaired by the MWC scaffolds, and the effectiveness of bone defect healing for MWC scaffolds were obviously better than that for WP scaffolds, indicating that the MWC scaffolds could promote the restoration of bone defects.

The histological elevation of H\&E staining confirmed that more new bone tissues could be formed in the MWC scaffolds as compared with WP scaffolds, indicating that the MWC scaffolds could promote the new bone regeneration. Masson trichrome staining of histological sections could provide the supplementary information of the in vivo osteogenesis and scaffolds degradation as compared with H\&E staining. ${ }^{29}$ The results showed that the percentage ratio of new bone and mature bone increased with time for the MWC scaffolds while the percentage ratio of material residual decreased with time. At 12 weeks, the percentage ratio of new bone, mature bone, and residual for the MWC scaffolds were $86 \%, 8 \%$, and $0 \%$ while for the WP scaffolds were $61 \%, 2 \%$, and $0 \%$, respectively. The results indicated that the percentage ratio of new bone and mature bone for the MWC scaffolds was significantly higher than WP scaffolds. The Masson trichrome staining further offered the evidence of the promoted effects of MWC scaffolds on new bone formation and material degradation in vivo.

The histomorphometry analysis based on the H\&E and Masson trichrome staining suggested that the MWC scaffolds could stimulate a more effective new bone tissue growth, which increased the speed and quality of bone regeneration and remodeling. ${ }^{30}$ To represent the osteogenic progression, immunohistochemistry was performed to detect the expression of BMP-2, which is secreted at the beginning of osteoid matrix deposition. ${ }^{31}$ The immunohistochemical staining results showed that the BMP-2 staining intensity for the MWC scaffolds increased with time and exhibited obviously high intensity as compared with WP scaffolds at 12 weeks. Furthermore, the positive expression ratio of BMP-2 for the MWC scaffolds was significantly higher than WP scaffolds at 8 and 12 weeks. The immunohistochemical analysis further offered the direct evidence of the stimulatory effects of MWC scaffolds on osteogenic-related cell differentiation and new bone formation.

Magnesium is an attractive element in biomaterials for bone tissue engineering applications because its incorporation in material compositions may stimulate new bone formation and improve bone healing. ${ }^{32}$ In this study, the results of SRmCT, histomorphometric, and immunohistochemical analyses showed that both in early- and late-stage implantations, MWC scaffolds promoted more osteogenesis than WP scaffolds, and in late-stage implantations, the rate of new bone formation was faster in MWC scaffolds than WP scaffolds. These results revealed that the MWC scaffolds 
containing MP significantly promoted new bone formation, and the MWC scaffolds had better osteogenic properties than WP scaffolds. It can be suggested that during the bone repair process, magnesium ion and inorganic phosphate (MWC degradation) are gradually released into the surrounding microenvironment, which could be benefit for the bone regeneration and improve bone defect healing. In summary, the MWC scaffolds with good biocompatibility, osteogenesis, and degradability could be a promising bioactive scaffold for bone repair.

\section{Conclusion}

Bioactive scaffolds of MWCs were fabricated in this study. The results showed that MWC scaffolds were well-interconnected macroporous structures and some micropores were found on the walls of the macroporores. The MWC scaffolds could be degradable in PBS and produced a weak alkaline environment, which might be benefit for the cell growth. In cell culture experiments, the results showed that the MWC scaffolds significantly promoted cell proliferation, differentiation, and growth into the scaffolds. The results showed that the MWC scaffolds significantly promoted new bone formation, and the degradation of the MWC scaffolds remarkably enhanced the new bone ingrowth in vivo. Furthermore, the immunohistochemistry results further offered the evidence of the stimulatory effects of MWC scaffolds on osteogenicrelated cell differentiation and in vivo osteogenesis. In short, the MWC scaffolds with good biocompability and degradability promoted new bone regeneration.

\section{Acknowledgments}

This study was supported by grants from the National Natural Science Foundation of China (No 81571887) and the National High Technology Research \& Development Program of China (863 Program) (2014AA021202).

\section{Disclosure}

The authors report no conflicts of interest in this work.

\section{References}

1. Huang $Y$, Jin X, Zhang X, et al. In vitro and in vivo evaluation of akermanite bioceramics for bone regeneration. Biomaterials. 2009;30(28): 5041-5048

2. Seyedraoufi ZS, Mirdamadi S. Effects of pulse electrodeposition parameters and alkali treatment on the properties of nano hydroxyapatite coating on porous $\mathrm{Mg}-\mathrm{Zn}$ scaffold for bone tissue engineering application. Mater Chem Phys. 2014;148(3):519-527.

3. Sun F, Zhou H, Lee J. Various preparation methods of highly porous hydroxyapatite/polymer nanoscale biocomposites for bone regeneration. Acta Biomater. 2011;7:3813-3828.

4. Milovanovic P, Potocnik J, Stoiljkovic M, et al. Nanostructure and mineral composition of trabecular bone in the lateral femoral neck: implications for bone fragility in elderly women. Acta Biomater. 2011;7(9):3446-3451.
5. Ye X, Cai S, Dou Y, et al. Bioactive glass-ceramic coating for enhancing the in vitro corrosion resistance of biodegradable $\mathrm{Mg}$ alloy. Appl Surf Sci. 2012;259:799-805.

6. Mueller W-D, Lucia Nascimento M, Lorenzo de Mele MF. Critical discussion of the results from different corrosion studies of $\mathrm{Mg}$ and $\mathrm{Mg}$ alloys for biomaterial applications. Acta Biomater. 2010;6(5):1749-1755.

7. Roohani-Esfahani SI, Nouri-Khorasani S, Lu ZF, Appleyard RC, Zreiqat $\mathrm{H}$. Effects of bioactive glass nanoparticles on the mechanical and biological behavior of composite coated scaffolds. Acta Biomater. 2011;7(3):1307-1318.

8. Klammert U, Ignatius A, Wolfram U, Reuther T, Gbureck U. In vivo degradation of low temperature calcium and magnesium phosphate ceramics in a heterotopic model. Acta Biomater. 2011;7(9):3469-3475.

9. Diba M, Goudouri O-M, Tapia F, Boccaccini AR. Magnesiumcontaining bioactive polycrystalline silicate-based ceramics and glassceramics for biomedical applications. Curr Opin Solid State Mater Sci. 2014;18(3):147-167.

10. Farraro KF, Kim KE, Woo SL, Flowers JR, McCullough MB. Revolutionizing orthopaedic biomaterials: The potential of biodegradable and bioresorbable magnesium-based materials for functional tissue engineering. J Biomech. 2014;47(9):1979-1986.

11. Čapek J, Vojtěch D. Effect of sintering conditions on the microstructural and mechanical characteristics of porous magnesium materials prepared by powder metallurgy. Mater Sci Eng C Mater Biol Appl. 2014;35: 21-28.

12. Kunjukunju S, Roy A, Ramanathan M, Lee B, Candiello JE, Kumta PN. A layer-by-layer approach to natural polymer-derived bioactive coatings on magnesium alloys. Acta Biomater. 2013;9(10):8690-8703.

13. Xu H, Cai S, Sellers A, Yang Y. Electrospun ultrafine fibrous wheat glutenin scaffolds with three-dimensionally random organization and water stability for soft tissue engineering. J Biotechnol. 2014;184:179-186.

14. Gomez-Martínez D, Partal P, Martínez I, Gallegos C. Rheological behaviour and physical properties of controlled-release gluten-based bioplastics. Biores Technol. 2009;100(5):1828-1832.

15. Zhang Y, Venugopal JR, El-Turki A, Ramakrishna S, Su B, Lim CT. Electrospun biomimetic nanocomposite nanofibers of hydroxyapatite/ chitosan for bone tissue engineering. Biomaterials. 2008;29(32): 4314-4322.

16. Dong J, Asandei AD, Parnas RS. Aqueous electrospinning of wheat gluten fibers with thiolated additives. Polymer. 2010;51(14):3164-3172.

17. Zhai W, Lu H, Wu C, Chen L, Lin X, Naoki K, et al. Stimulatory effects of the ionic products from $\mathrm{Ca}-\mathrm{Mg}-\mathrm{Si}$ bioceramics on both osteogenesis and angiogenesis in vitro. Acta Biomater. 2013;9(8):8004-8014.

18. Duan B, Wang M, Zhou WY, Cheung WL, Li ZY, Lu WW. Three-dimensional nanocomposite scaffolds fabricated via selective laser sintering for bone tissue engineering. Acta Biomater. 2010;6(12): 4495-4505.

19. Correia C, Bhumiratana S, Yan L-P, Oliveira AL, Gimble JM, RockwoodD, et al. Development of silk-based scaffolds for tissue engineering of bone from human adipose-derived stem cells. Acta Biomater. 2012;8(7): 2483-2492.

20. Liu YS, Huang QL, Kienzle A, Müller WEG, Feng QL. In vitro degradation of porous PLLA/pearl powder composite scaffolds. Mater Sci Eng C. 2014;38:227-234.

21. Jiang T, Nukavarapu SP, Deng M, et al. Chitosan-poly(lactide-coglycolide) microsphere-based scaffolds for bone tissue engineering: in vitro degradation and in vivo bone regeneration studies. Acta Biomater. 2010;6(9):3457-3470

22. Surmenev RA, Surmeneva MA, Ivanova AA. Significance of calcium phosphate coatings for the enhancement of new bone osteogenesis A review. Acta Biomater. 2014;10(5):557-579.

23. Hild N, Tawakoli PN, Halter JG, et al. pH-dependent antibacterial effects on oral microorganisms through pure PLGA implants and composites with nanosized bioactive glass. Acta Biomater. 2013;9(11): 9118-9125.

24. Garripelli VK, Kim JK, Namgung R, Kim WJ, Repka MA, Jo S. A novel thermosensitive polymer with $\mathrm{pH}$-dependent degradation for drug delivery. Acta Biomater. 2010;6(2):477-485. 
25. Chan-Chan LH, Solis-Correa R, Vargas-Coronado RF, et al. Degradation studies on segmented polyurethanes prepared with HMDI, PCL and different chain extenders. Acta Biomater. 2010;6(6):2035-2044.

26. Kang Y, Kim S, Fahrenholtz M, Khademhosseini A, Yang Y. Osteogenic and angiogenic potentials of monocultured and co-cultured humanbone-marrow-derived mesenchymal stem cells and human-umbilicalvein endothelial cells on three-dimensional porous beta-tricalcium phosphate scaffold. Acta Biomateri. 2013;9(1):4906-4915.

27. Györgyey Á, Ungvári K, Kecskeméti G, et al. Attachment and proliferation of human osteoblast-like cells (MG-63) on laser-ablated titanium implant material. Mater Sci Eng C. 2013;33(7):4251-4259.

28. Varanasi VG, Saiz E, Loomer PM, et al. Enhanced osteocalcin expression by osteoblast-like cells (MC3T3-E1) exposed to bioactive coating glass $\left(\mathrm{SiO}_{2}-\mathrm{CaO}-\mathrm{P}_{2} \mathrm{O}_{5}-\mathrm{MgO}-\mathrm{K}_{2} \mathrm{O}-\mathrm{Na}_{2} \mathrm{O}\right.$ system $)$ ions. Acta Biomater. 2009;5(9):3536-3547.
29. He S, Xia T, Wang H, Wei L, Luo X, Li X. Multiple release of polyplexes of plasmids VEGF and bFGF from electrospun fibrous scaffolds towards regeneration of mature blood vessels. Acta Biomater. 2012; $8(7): 2659-2669$

30. Jeong SI, Kim B-S, Kang SW, et al. In vivo biocompatibilty and degradation behavior of elastic poly(1-lactide-co- $\varepsilon$-caprolactone) scaffolds. Biomaterials. 2004;25(28):5939-5946.

31. Bosetti M, Cannas M. The effect of bioactive glasses on bone marrow stromal cells differentiation. Biomaterials. 2005;26(18):3873-3879.

32. Bobe K, Willbold E, Morgenthal I, et al. In vitro and in vivo evaluation of biodegradable, open-porous scaffolds made of sintered magnesium W4 short fibres. Acta Biomater. 2013;9(10):8611-8623.
International Journal of Nanomedicine

\section{Publish your work in this journal}

The International Journal of Nanomedicine is an international, peerreviewed journal focusing on the application of nanotechnology in diagnostics, therapeutics, and drug delivery systems throughout the biomedical field. This journal is indexed on PubMed Central, MedLine, CAS, SciSearch $®$, Current Contents $\AA /$ Clinical Medicine,

\section{Dovepress}

Journal Citation Reports/Science Edition, EMBase, Scopus and the Elsevier Bibliographic databases. The manuscript management system is completely online and includes a very quick and fair peer-review system, which is all easy to use. Visit http://www.dovepress.com/ testimonials.php to read real quotes from published authors.

Submit your manuscript here: http://www.dovepress.com/international-journal-of-nanomedicine-journal 